\title{
Electrospark Deposition: Mass Transfer
}

\author{
Orhan Sahin and Alexandre V. Ribalko \\ Gebze Institute of Technology \\ Turkey
}

\section{Introduction}

Electrospark alloying (ESA) is one of the surface modification methods to change physical and chemical properties of metal surfaces. It was developed by the Soviet scientists, B.R. Lazarenko and N.I. Lazarenko. The core of this method is the phenomenon of material erosion of both electrodes as a result of the electric discharge between them in a gaseous environment and subsequent mass transfer from one of them to the other, basically from anode to the cathode (Lazarenko, 1951; Lazarenko, 1976).

The anode (treating electrode) usually is a rod with several $\mathrm{mm}$ square cross sectional area. Comparing with treating electrode, the cathode (substrate) has significantly larger size and surface area. Both of them are electrically conductive. After the application of a current pulse, a spark discharge takes place between treating electrode and substrate. Following spark discharge, part of the tip of treating electrode and a corresponding spot on substrate melt. Molten spot on the substrate forms a swallow molten pool. Some of the molten tip of treating electrode material transfers to the substrate in the form of molten droplets, mixes with its molten pool and usually solidifies as in the form of splash. By scanning substrate surface, so many splashes could be deposited on it. As a Consequence of single or multiple scanning of substrate surface, a deposit having chemical composition same as treating electrode forms on the substrate.

According to Lazarenko (1951), the size and sign of electrical erosion at the electrodes, consequently, the mass transfer from the treating electrode to the substrate depends on chemical composition of electrode materials, environment between electrodes and parameters of the electrical pulse. It is obvious that for ESA in air, size of erosion depends basically on chemical composition of electrodes and pulse energy, in turn pulse parameters, pulse amplitude and pulse duration. Therefore, for a given pair of electrodes, mass transfer depends only on electrical parameters of pulses. It was experimentally shown that, the mass gain of substrate is limited, i.e. it is impossible to obtain thick electrospark coating. According to the author (Lazarenko, 1976), the limitation of mass gain of substrate depends on several factors. Lazarenko named them as: change in chemical properties of molten droplet during its transfer to the substrate; change in chemical properties of substrate surface due to mixing with molten droplet ejected from treating electrode and oxidation in air; radical changes arising in alloyed substrate surface - occurrence and accumulation of defects in crystal lattice preventing diffusion; occurrence of residual stress etc. She has also reported that even under the non-oxidizing gas environment-such as argon, helium, hydrogen, there was still limitation on coating thickness. In this case, the processing time till limitation was slightly longer than that of the processing in air. 
Many years past since then; however, published scientific studies on ESA shows that, breakthrough in technology to form thick coating has not been achieved yet. This problem could partially be solved by using pulses providing maximum erosion (mass loss) of the treating electrode and maximum mass gain by the substrate. The process of mass transfer must be completed before any one of the factors described above could have sufficient time to be fully effective (Lazarenko, 1976).

Thus, in order to determine the condition of maximum mass transfer from treating electrode to substrate, it is necessary to study mass transfer characteristics of electrodes as a function of pulse durations. The literature review on this question shows that, the range of pulse durations is from $10^{-5} \mathrm{sec}$ (short durations), to $10^{-3}-10^{-2} \mathrm{sec}$ (long durations). The pulse duration was limited by possibility of generating current pulses with amplitude of $100 \mathrm{~A}$ and voltage of $100 \mathrm{~V}$ at lower side of pulse duration range and change in polarity of mass transfer and increase in heat content of the substrate at upper side of pulse duration range. Thus, the possible interval of pulse durations for ESA is from $10 \mu$ s to $10000 \mu \mathrm{s}$.

Lazarenko (1957) investigated mass transfer characteristics of ESA process only in the range of $50 \mu \mathrm{s}$ to $300 \mu \mathrm{s}$. For alloying, she used sinusoidal pulses generated by the discharge of capacitor on spark loading. According to the Lazarenko (1957), the optimal pulse duration for ESA is between $50 \mu \mathrm{s}$ to $300 \mu \mathrm{s}$. The following years and practically at present, same pulse durations have been used for ESA, because above pulse range was considered as a base to fabricate ESA installations.

Zolotih (1957) investigated the dependence of erosion of treating electrode to pulse duration with reference to the electrospark dimensional machining (EDM) of metals. The range of sinusoidal pulse duration was $100 \mu \mathrm{s}-1100 \mu \mathrm{s}$. It is interesting to notice that in EDM case the mass loss of treating electrode versus processing time curve has a maximum. The emergence of the maximum depends on pulse duration and physico-chemical properties of electrodes. Dependence of erosion of treating electrode to the pulse shape (Rybalko et al., 2003a) revealed that, ESA with application of square pulses was more productive. Therefore, to form square pulses, an ESA installation has been developed (Rybalko et al., 2003b, 2003c) (see, Fig 1a and 1b). The current pulse shaper was executed on the basis of single-cycle electric generator with a transistor switchboard. It is capable to form a pulse with desired parameters by a method of pulse-duration modulation. Such approach allows producing a current pulse with various amplitude, duration and shape without changing the parameters of pulse forming circuit, U, C, L and R. The master generator of the pulse shaper regulate the duration of its pulses and pauses in steps of 200 nanoseconds. The pulse amplitude could be increased in the order of 3 A. For the case of forming more complicated pulse shape, the approach of pulse-duration modulation was used.

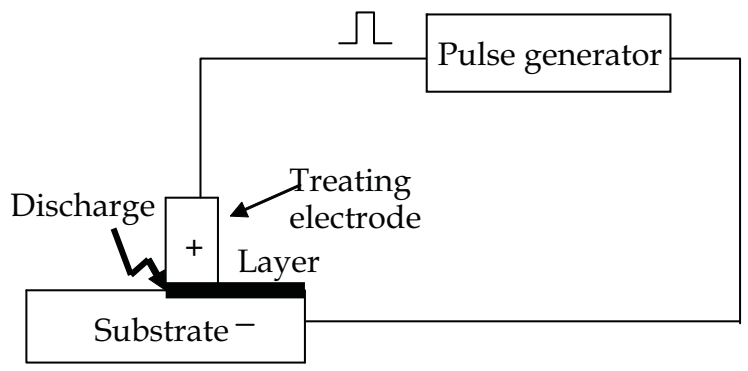

Fig. 1a. The diagram of the ESA installation 


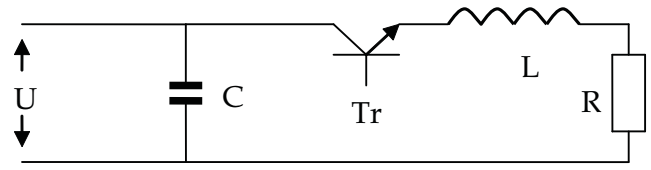

(b1)

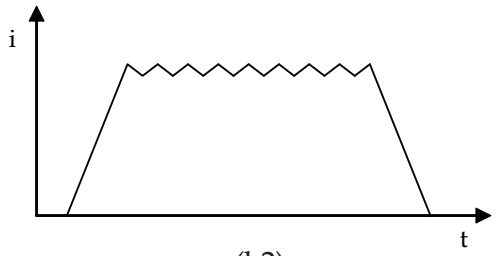

(b2)

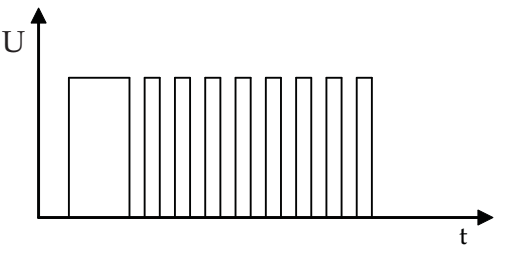

(b3)

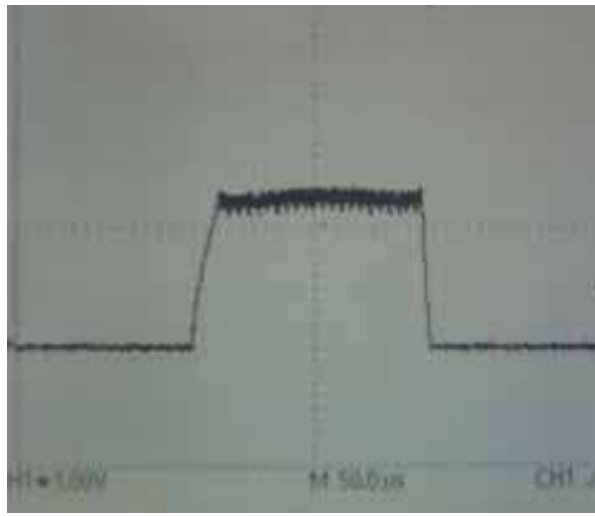

(b4)

Fig. 1b. Generating of a pulse by pulse-width modulation. The electrical discharge circuit ( $\mathrm{Tr}$ is the transistor, $\mathrm{U}$ is the voltage of power supply, $\mathrm{C}, \mathrm{L}$ and $\mathrm{R}$ are the capacitance, inductance and resistance (including the load) of the discharge circuit, respectively) (b1). A representative current pulse oscillogram (b2) could be formed by on-off switching of the transistor (b3). $t$ and $\mathrm{i}$ are the time and current, respectively. The on-off switching of transistor was operated by programmed voltage pulses from pulse oscillator. A real current pulse oscillogram, pulse amplitude is $300 \mathrm{~A}$ and pulse duration is $200 \mu \mathrm{s}(\mathrm{b} 4)$

The present installation is capable of forming pulse groups with various parameters. Power consumption of the installation is $1000 \mathrm{~W}$. The stabilized output voltage of the converter is $40 \mathrm{~V}$. Range of energy and duration of pulse is $0,25 \times 10^{-3}-15 \mathrm{~J}$ and $2-8000 \mu$ s respectively. Range of pulse frequency is $2-120000 \mathrm{~Hz}$. The upper boundary of frequencies is used for minimum pulse amplitude of $15 \mathrm{~A}$.

For a chosen voltage, taking into account the full resistance of discharge circuit, the average rate of increase of pulse first front (first slope of pulse) is $14,4 \mathrm{~A} / \mu$ s till to the amplitude of 1000 A. Continuous sliding of the processing electrode on the substrate surface back and forth, provided the possibility of discharge initiation with explosion of contacting micro roughness and formation of plasma channel at any moment of time (Rybalko et al., 2000). 
The total electricity through the inter-electrode gap was kept constant at 3 Coulomb as a base for comparison of experimental results.

\section{Experimental results of electrospark alloying}

The following sets of experiments were carried out in order to have a broad idea about the mass transfer behavior from the treating electrode to the substrate. Pulse amplitudes ranging from $100 \mathrm{~A}$ to $1000 \mathrm{~A}$ and pulse duration ranging from $25 \mu$ s to $4000 \mu$ s were used (Rybalko et al., 2003d, 2004a, 2004b). The aim is to maximize mass gain of substrate at the initial stage of ESA, i.e. first layer of deposition, by increasing pulse energy. Because, as explained by Lazarenko (1976), when chemical composition of substrate surface becomes same as treating electrode after a single or multiple layer of deposition, mass transfer ceases down. Therefore, erosion of treating electrode should be as high as possible for the first layer of deposition. Experimental results revealed that one of the reasons limiting the thickness of deposit is the destruction of the layer already deposited during processing (Rybalko et al., 2003e). This was due to local evaporation of material underneath the outer surface of deposit. Evaporation was caused by the heat provided locally by spark discharges during second layer of deposition. Upon further processing evaporation intensifies and even cavities form. The point is to find out a common criterion for coating destruction during processing.

The mass loss of the treating electrode, the mass gain of the substrate, the calculation of mass transfer coefficient, the measurement of thickness and roughness (parameter Ra) of deposited layers, and some characteristics of the ESA process were studied for every 30 seconds for a total 3 minutes of processing. The amount of mass loss of the treating electrode and the amount of mass gain of the substrate at each time interval of 30 seconds for various pulse parameters (amplitude and duration) as a function of processing time were given in Figs 2-7. Usually in this type of ESA studies, not the mass difference between two successive measurements, but the cumulative mass change of the treating electrode and substrate versus processing time has been used to describe the change in the mass of the electrodes. The treating electrode and substrate were WC92-Co8 with cross section of $8 \mathrm{~mm}^{2}$ and steel 35 with an area of $1 \mathrm{~cm}^{2}$, respectively.

Mass loss curves of treating electrode and mass gain curves of substrate were not linear from the very beginning of alloying, for all investigated range of pulse parameters. Nonlinearity of the mass loss curves of treating electrode at the initial stage of the electrospark alloying was attributed to the nature of ESA method itself. After approximately 2 minutes of processing, mass loss of treating electrode leveled off and became stationary for the deposition with pulse amplitudes of $100 \mathrm{~A}, 200 \mathrm{~A}$ and $400 \mathrm{~A}$. In case of deposition with pulse amplitude of $600 \mathrm{~A}, 800 \mathrm{~A}$ and $1000 \mathrm{~A}$, this happened after approximately 1 minute of processing. Any increase in pulse duration caused: an increase in erosion of treating electrode at the initial stage of alloying, i.e. the first layer of deposition, an increase in the amount of stationary mass loss of the treating electrode, stationary level to emerge in shorter processing time.

Substrate mass gain curves were not linear either. After gradually decreasing they eventually became asymptotic to the horizontal axis. When substrate mass gain curves became asymptotic, mass loss of treating electrode became stationary. Upon further alloying the mass increment of substrate became negative. That is, instead of gaining mass, substrate started to lose mass. This is a sign for the beginning of destruction of deposit already formed. Moreover, for pulse amplitudes of $600 \mathrm{~A}, 800 \mathrm{~A}$ and $1000 \mathrm{~A}$, mass gain of substrate sharply decreased down from the very beginning of processing, (Fig. 5-7), and almost for all experimental conditions, they were negative. These curves were indicated by dotted lines. 


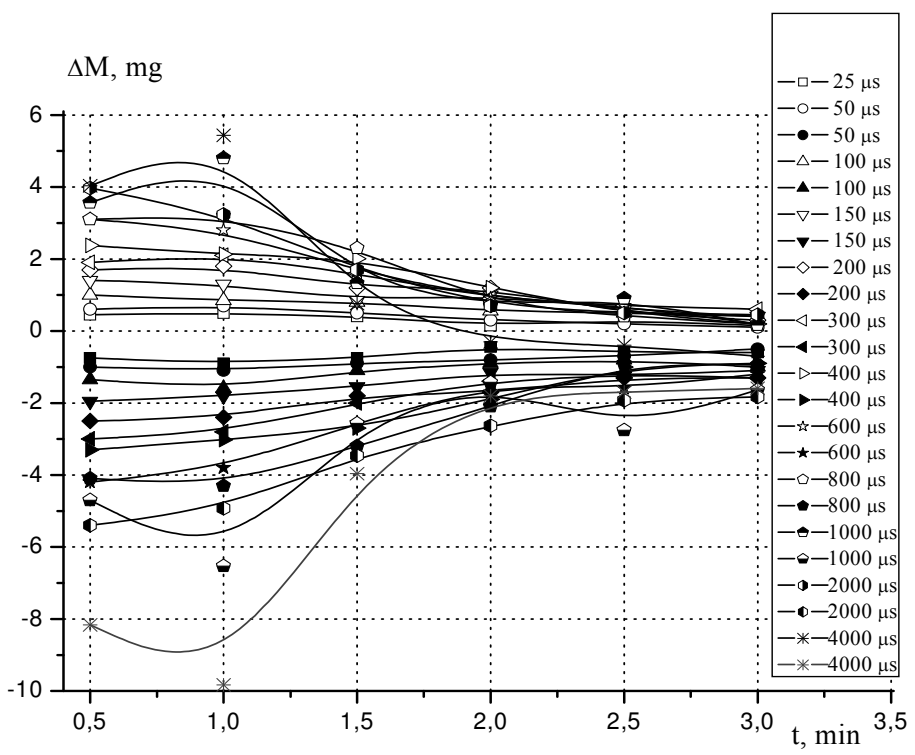

Fig. 2. Mass loss of treating electrode and mass gain of substrate (solid dots) as a function of pulse energy for a period of 3 minutes of processing. Pulse amplitude was 100 A. Pulse duration was variable

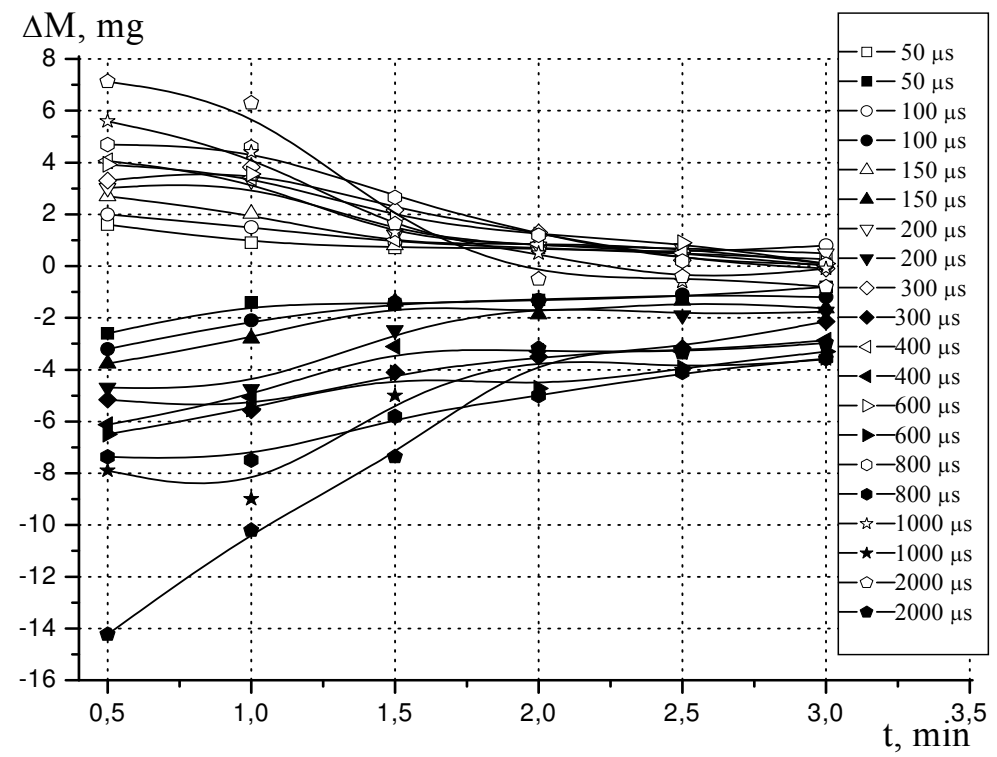

Fig. 3. Mass loss of treating electrode and mass gain of substrate (solid dots) as a function of pulse energy for a period of 3 minutes of processing. Pulse amplitude was 200 A. Pulse duration was variable 


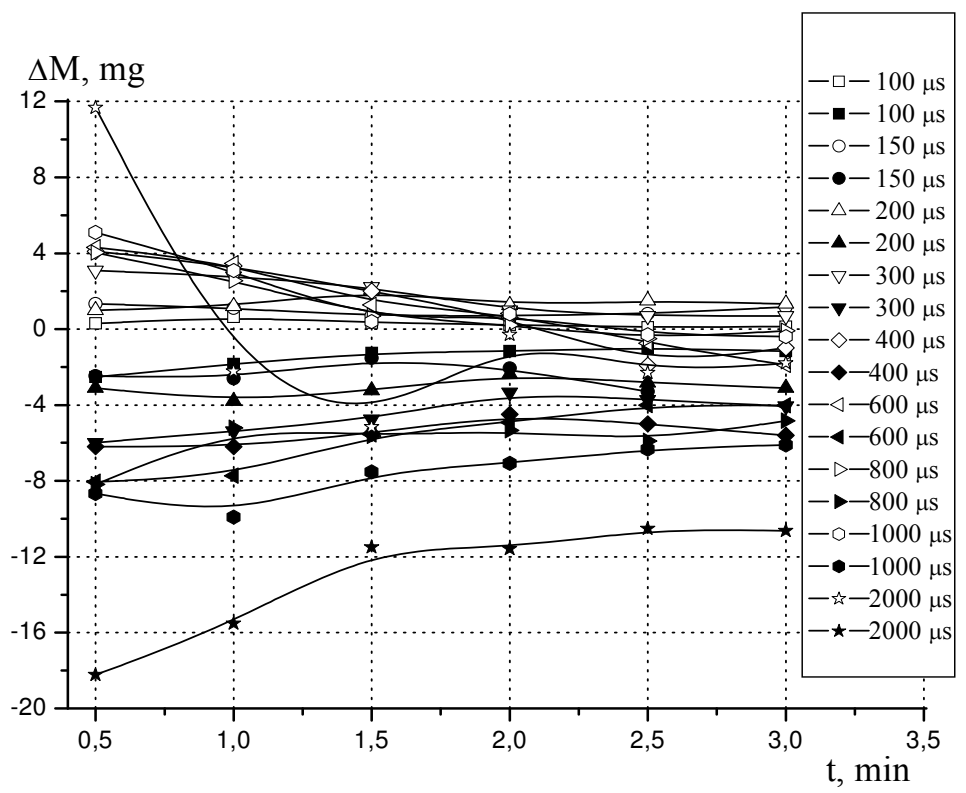

Fig. 4. Mass loss of treating electrode and mass gain of substrate (solid dots) as a function of pulse energy for a period of 3 minutes of processing. Pulse amplitude was 400 A. Pulse duration was variable

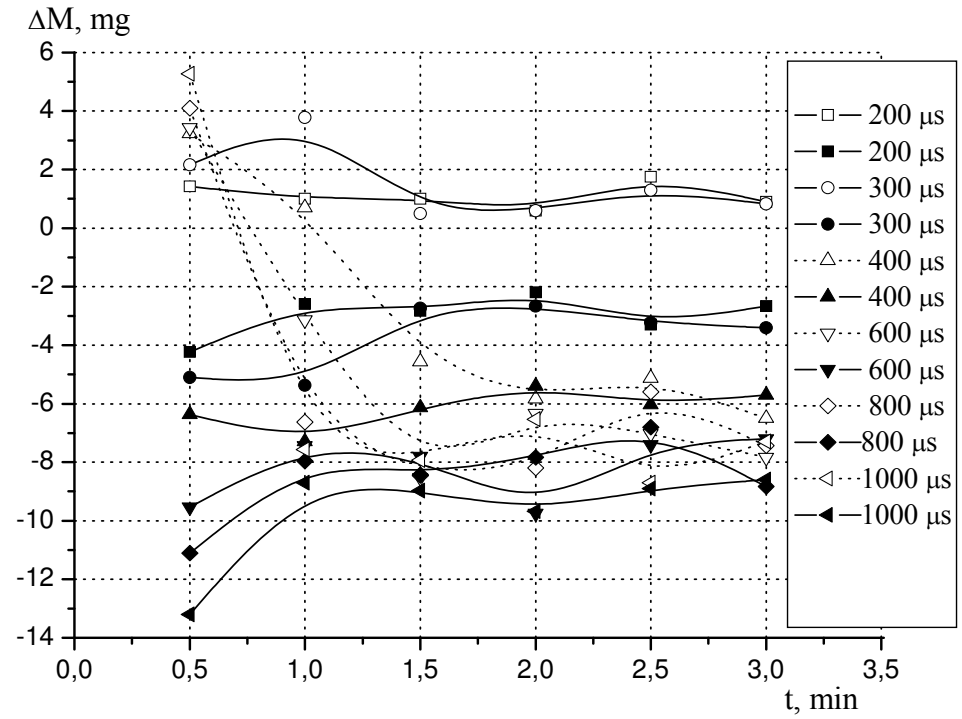

Fig. 5. Mass loss of treating electrode and mass gain of substrate (solid dots) as a function of pulse energy for a period of 3 minutes of processing. Pulse amplitude was $600 \mathrm{~A}$. Pulse duration was variable 


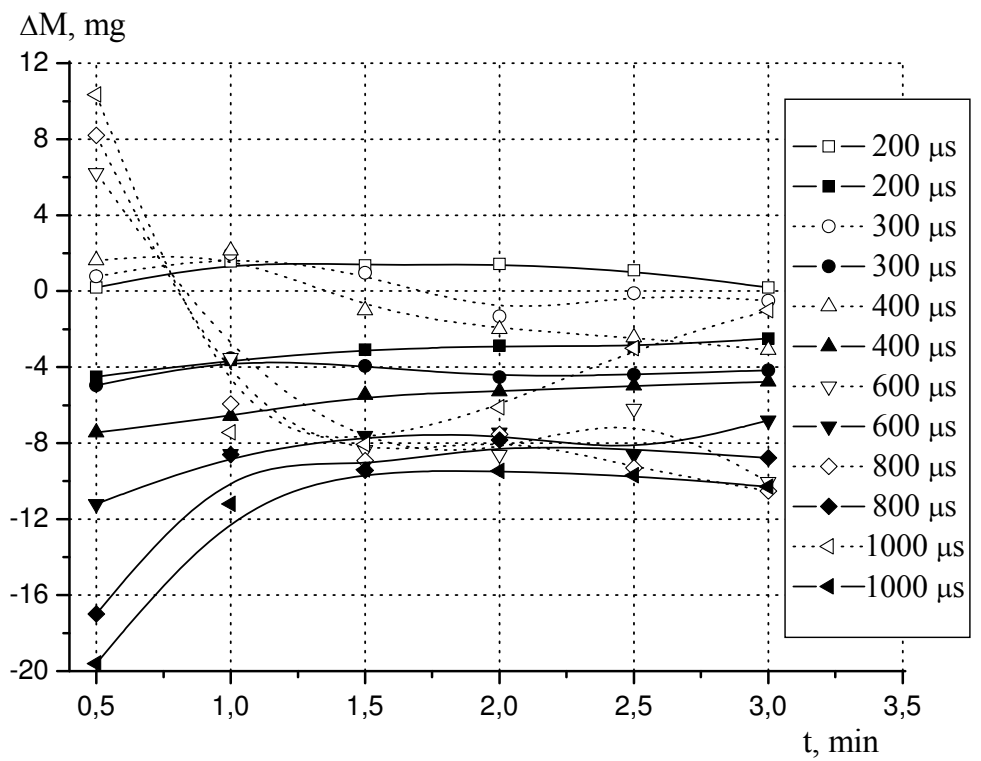

Fig. 6. Mass loss of treating electrode and mass gain of substrate (solid dots) as a function of pulse energy for a period of 3 minutes of processing. Pulse amplitude was 800 A. Pulse duration was variable

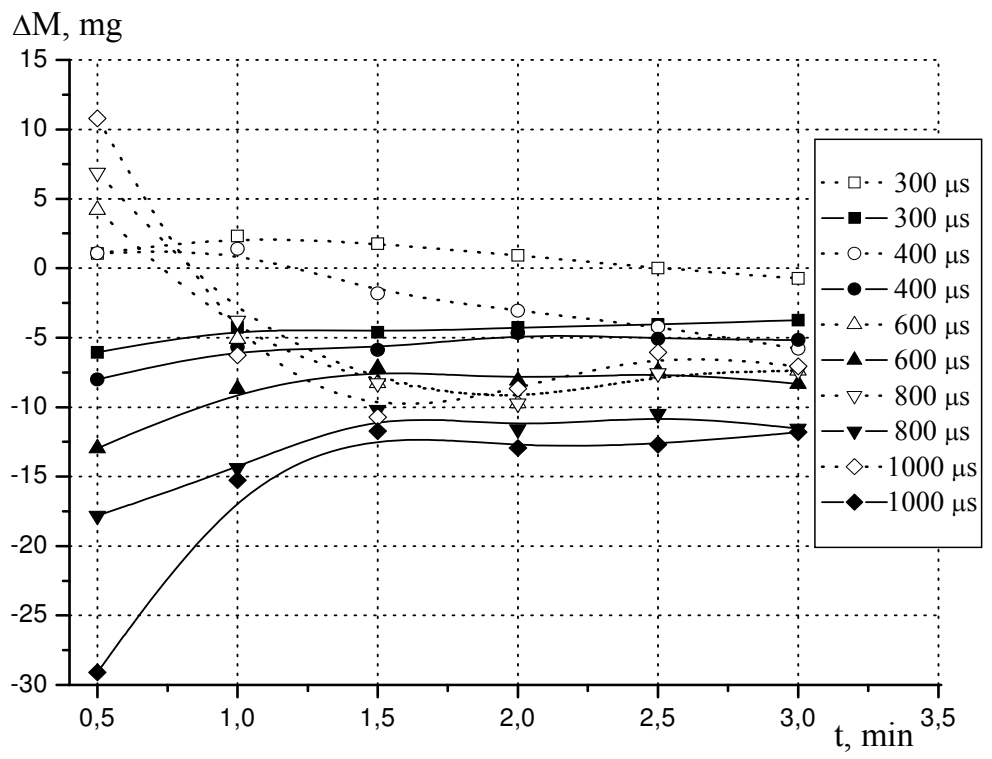

Fig. 7. Mass loss of treating electrode and mass gain of substrate (solid dots) as a function of pulse energy for a period of 3 minutes of processing. Pulse amplitude was 1000 A. Pulse duration was variable 
Longer pulse durations caused higher mass gain of substrate at the first layer of deposition and shorter processing time till to the beginning of mass loss by these substrates. Higher pulse amplitude also was accompanied by an increase in substrate mass gain at the initial stage of alloying. The only exceptional data is that, in case of ESA with pulse amplitude of $1000 \mathrm{~A}$, comparing to the case of $800 \mathrm{~A}$, any significant increase in mass gain of substrate was not obtained.

Since, environment and initial condition of electrode materials were same for all experiments, the difference in experimental results was due to the difference in pulse parameters (pulse energy) for only the processing time of 30 seconds (first layer of deposition). This is not true for second and third layers of deposition. The mass gain of substrates, in turn surface properties of substrates, after first layer of deposition was all different from each other. Therefore, only the experimental results of first layer of deposition including some characteristic of processing were used to form a base, Tables 1-6, in order to find out the effect of pulse energy on mass transfer. Mass transfer coefficients were calculated from the data of mass transfer during the first 30 seconds of alloying.

\begin{tabular}{|c|c|c|c|c|c|c|c|c|c|c|c|c|}
\hline $\begin{array}{c}\text { Pulse } \\
\text { duration }(\mu \mathrm{s})\end{array}$ & 25 & 50 & 100 & 150 & 200 & 300 & 400 & 600 & 800 & 1000 & 2000 & 4000 \\
\hline $\begin{array}{c}\text { Pulse } \\
\text { energy }(\mathrm{J})\end{array}$ & 0,032 & 0,08 & 0,17 & 0,233 & 0,297 & 0,529 & 0,72 & 1,08 & 1,44 & 1,7 & 3,4 & 6,79 \\
\hline $\begin{array}{c}\text { Frequency } \\
(\mathrm{Hz})\end{array}$ & 1613 & 645 & 309 & 219 & 178 & 99 & 71 & 47 & 36 & 30 & 15 & 8 \\
\hline $\begin{array}{c}\text { Processing } \\
\text { electricity }(\mathrm{C})\end{array}$ & 3,00 & 3,03 & 2,99 & 3,00 & 3,11 & 3,08 & 3,01 & 2,99 & 3,05 & 3 & 3 & 3,2 \\
\hline $\begin{array}{c}\text { Time t } \mathrm{t}_{1} \text { to scan } \\
\text { 1cm }{ }^{2}(\mathrm{sec})\end{array}$ & 50 & 50 & 50 & 45 & 45 & 45 & 55 & 50 & 55 & 55 & 70 & 60 \\
\hline $\begin{array}{c}\text { Mass loss of } \\
\text { anode }(\mathrm{mg})\end{array}$ & 1,25 & 1,67 & 2,25 & 2,92 & 3,75 & 4,5 & 6,05 & 7 & 7,52 & 10,3 & 12,1 & 17,99 \\
\hline $\begin{array}{c}\text { Mass gain of } \\
\text { cathode }(\mathrm{mg})\end{array}$ & 0,75 & 1,00 & 1,66 & 2,1 & 2,55 & 2,85 & 4,35 & 5,17 & 5,68 & 7,66 & 8,4 & 9,46 \\
\hline $\begin{array}{c}\text { Mass transfer } \\
\text { coefficient }\end{array}$ & 0,6 & 0,6 & 0,74 & 0,68 & 0,68 & 0,63 & 0,72 & 0,74 & 0,75 & 0,74 & 0,69 & 0,76 \\
\hline $\begin{array}{c}\text { Surface } \\
\text { roughness }(\mu \mathrm{m})\end{array}$ & 2,65 & 2,77 & 3,0 & 3,25 & 3,35 & 3,71 & 4,35 & 4,9 & 5,36 & 7,2 & 8,97 & 12,03 \\
\hline $\begin{array}{c}\text { Recommended } \\
\text { number of } \\
\text { layers }\end{array}$ & 3 & 3 & 3 & $2-3$ & $2-3$ & $2-3$ & 2 & 2 & $1-2$ & 1 & 1 & 1 \\
\hline $\begin{array}{c}\text { Coating } \\
\text { thickness till to } \\
\text { failure }(\mu \mathrm{m})\end{array}$ & $10 \pm 4$ & $13 \pm 7$ & $13 \pm 5$ & $16 \pm 6$ & $17 \pm 5$ & $20 \pm 6$ & $22 \pm 6$ & $23 \pm 6$ & $35 \pm 10$ & $35 \pm 20$ & $45 \pm 35$ & $60 \pm 50$ \\
\hline
\end{tabular}

Table 1. Some parameters of processing. Pulse amplitude is $100 \mathrm{~A}$ 


\begin{tabular}{|c|c|c|c|c|c|c|c|c|c|c|}
\hline $\begin{array}{c}\text { Pulse } \\
\text { duration }(\mu \mathrm{s})\end{array}$ & 50 & 100 & 150 & 200 & 300 & 400 & 600 & 800 & 1000 & 2000 \\
\hline $\begin{array}{c}\text { Pulse } \\
\text { energy }(\mathrm{J})\end{array}$ & 0,097 & 0,257 & 0,427 & 0,602 & 0,927 & 1,28 & 1,9 & 2,72 & 3,31 & 6,74 \\
\hline $\begin{array}{c}\text { Frequency } \\
(\mathrm{Hz})\end{array}$ & 528 & 198 & 119 & 92 & 55 & 39 & 26 & 19 & 16 & 8 \\
\hline $\begin{array}{l}\text { Processing } \\
\text { electricity }(\mathrm{C})\end{array}$ & 2,99 & 2,997 & 2,99 & 3,25 & 3 & 2,95 & 2,91 & 3,04 & 3,12 & 3,17 \\
\hline $\begin{array}{c}\text { Time } t_{1} \text { to } \\
\text { scan } 1 \mathrm{~cm}^{2}(\mathrm{sec})\end{array}$ & 50 & 40 & 40 & 40 & 40 & 50 & 60 & 65 & 65 & 60 \\
\hline $\begin{array}{l}\text { Mass loss of } \\
\text { anode }(\mathrm{mg})\end{array}$ & 2,33 & 3,47 & 4,27 & 5,03 & 5,59 & 8,6 & 11,2 & 13,0 & 16,1 & 16,9 \\
\hline $\begin{array}{l}\text { Mass gain of } \\
\text { cathode }(\mathrm{mg})\end{array}$ & 1,33 & 2,13 & 2,66 & 3,6 & 4,02 & 5,5 & 7,46 & 8,11 & 10,1 & 10 \\
\hline $\begin{array}{c}\text { Mass transfer } \\
\text { coefficient }\end{array}$ & 0,57 & 0,61 & 0,62 & 0,72 & 0,72 & 0,64 & 0,67 & 0,62 & 0,63 & 059 \\
\hline $\begin{array}{c}\text { Surface } \\
\text { roughness }(\mu \mathrm{m})\end{array}$ & 3,07 & 3,12 & 4,1 & 4,61 & 5,01 & 6,8 & 7,42 & 8,83 & 9,98 & 11,67 \\
\hline $\begin{array}{c}\text { Recommended } \\
\text { number of layers }\end{array}$ & 3 & 3 & $3-2$ & 2 & 2 & $2-1$ & 1 & 1 & 1 & 1 \\
\hline $\begin{array}{l}\text { Coating thickness till } \\
\text { to failure }(\mu \mathrm{m})\end{array}$ & $12 \pm 7$ & $17 \pm 5$ & $32 \pm 5$ & $37 \pm 10$ & $41 \pm 10$ & $50 \pm 20$ & $55 \pm 20$ & $55 \pm 20$ & $55 \pm 25$ & $60 \pm 25$ \\
\hline
\end{tabular}

Table 2. Some parameters of processing. Pulse amplitude is $200 \mathrm{~A}$

\begin{tabular}{|c|c|c|c|c|c|c|c|c|c|}
\hline $\begin{array}{c}\text { Pulse } \\
\text { duration }(\mu \mathrm{s})\end{array}$ & 100 & 150 & 200 & 300 & 400 & 600 & 800 & 1000 & 2000 \\
\hline $\begin{array}{c}\text { Pulse } \\
\text { energy }(\mathrm{J})\end{array}$ & 0,342 & 0,639 & 1,02 & 1,68 & 2,39 & 3,77 & 5,12 & 6,48 & 13,3 \\
\hline $\begin{array}{c}\text { Frequency } \\
(\mathrm{Hz})\end{array}$ & 158 & 80 & 50 & 31 & 23 & 13 & 10 & 8 & 4 \\
\hline $\begin{array}{c}\text { Processing } \\
\text { electricity (C) }\end{array}$ & 3,002 & 3,008 & 3,009 & 3,066 & 3,23 & 3,108 & 3,01 & 3,048 & 3,13 \\
\hline $\begin{array}{c}\text { Time t } 1 \text { to } \\
\text { scan 1 } \mathrm{cm}^{2}(\mathrm{sec})\end{array}$ & 35 & 50 & 50 & 50 & 50 & 50 & 40 & 40 & 28 \\
\hline $\begin{array}{c}\text { Mass loss of } \\
\text { anode (mg) }\end{array}$ & 2,96 & 4,2 & 5,17 & 10 & 11,5 & 13,15 & 10,92 & 11,56 & 17,01 \\
\hline $\begin{array}{c}\text { Mass gain of } \\
\text { cathode (mg) }\end{array}$ & 0,35 & 2,27 & 1,67 & 5,17 & 5,52 & 6,47 & 5,38 & 6,8 & 10,9 \\
\hline $\begin{array}{c}\text { Mass transfer } \\
\text { coefficient }\end{array}$ & 0,12 & 0,54 & 0,32 & 0,52 & 0,48 & 0,49 & 0,59 & 0,59 & 0,64 \\
\hline $\begin{array}{c}\text { Surface } \\
\text { roughness }(\mu \mathrm{m})\end{array}$ & 3,79 & 4,42 & 6,32 & 10,1 & 11,7 & 12,48 & 13,62 & 15,45 & 14,69 \\
\hline $\begin{array}{c}\text { Recommended } \\
\text { number of layers }\end{array}$ & 3 & 2 & $2-1$ & $2-1$ & 1 & 1 & 1 & 1 & 1 \\
\hline $\begin{array}{c}\text { Coating thickness } \\
\text { till to failure }(\mu \mathrm{m})\end{array}$ & $16 \pm 5$ & $35 \pm 5$ & $50 \pm 20$ & $60 \pm 30$ & $65 \pm 30$ & $65 \pm 30$ & $75 \pm 40$ & $65 \pm 40$ & $100 \pm 80$ \\
\hline
\end{tabular}

Table 3. Some parameters of processing. Pulse amplitude is $400 \mathrm{~A}$ 


\begin{tabular}{|c|c|c|c|c|c|c|}
\hline $\begin{array}{c}\text { Pulse } \\
\text { duration }(\mu \mathrm{s})\end{array}$ & 200 & 300 & 400 & 600 & 800 & 1000 \\
\hline $\begin{array}{c}\text { Pulse } \\
\text { energy (J) }\end{array}$ & 1,13 & 2,19 & 3,35 & 5,34 & 7,31 & 9,39 \\
\hline $\begin{array}{c}\text { Frequency } \\
(\mathrm{Hz})\end{array}$ & 45 & 23 & 15 & 10 & 7 & 5 \\
\hline $\begin{array}{c}\text { Processing } \\
\text { electricity (C) }\end{array}$ & 2,997 & 2,967 & 2,955 & 3,14 & 3,01 & 2,763 \\
\hline $\begin{array}{c}\text { Time t to } \\
\text { scan 1cm } \text { (sec })^{2}\end{array}$ & 35 & 35 & 35 & 35 & 30 & 25 \\
\hline $\begin{array}{c}\text { Mass loss of } \\
\text { anode (m) }\end{array}$ & 4,9 & 5,95 & 7,43 & 11,12 & 11,1 & 11 \\
\hline $\begin{array}{c}\text { Mass gain of } \\
\text { cathode (mg) }\end{array}$ & 1,67 & 2,53 & 3,77 & 4 & 4,1 & 4,39 \\
\hline $\begin{array}{c}\text { Mass transfer } \\
\text { coefficient }\end{array}$ & 0,34 & 0,43 & 0,51 & 0,36 & 0,37 & 0,4 \\
\hline $\begin{array}{c}\text { Surface roughness } \\
(\mu \mathrm{m})\end{array}$ & 5,14 & 7,05 & 10,14 & 14,20 & 15,82 & 17,72 \\
\hline $\begin{array}{c}\text { Recommended } \\
\text { number of layers }\end{array}$ & 3 & 2 & 1 & 1 & 1 & 1 \\
\hline $\begin{array}{c}\text { Coating thickness } \\
\text { till to failure ( } \mu \mathrm{m})\end{array}$ & $35 \pm 15$ & $55 \pm 30$ & $65 \pm 40$ & $40 \pm 15$ & $70 \pm 50$ & $75 \pm 50$ \\
\hline
\end{tabular}

Table 4. Some parameters of processing. Pulse amplitude is $600 \mathrm{~A}$

\begin{tabular}{|c|c|c|c|c|c|c|}
\hline $\begin{array}{c}\text { Pulse } \\
\text { duration }(\mu \mathrm{s})\end{array}$ & 200 & 300 & 400 & 600 & 800 & 1000 \\
\hline $\begin{array}{c}\text { Pulse } \\
\text { energy (J) }\end{array}$ & 1,47 & 2,78 & 3,96 & 6,82 & 9,47 & 12,45 \\
\hline $\begin{array}{c}\text { Frequency } \\
(\mathrm{Hz})\end{array}$ & 35 & 18 & 13 & 8 & 5 & 4 \\
\hline $\begin{array}{c}\text { Processing } \\
\text { electricity (C) }\end{array}$ & 3,02 & 2,95 & 3,03 & 3,21 & 2,78 & 2,93 \\
\hline $\begin{array}{c}\text { Time t } \text { to } \\
\text { scan 1 } \mathrm{cm}^{2}(\mathrm{sec})\end{array}$ & 35 & 35 & 35 & 25 & 25 & 25 \\
\hline $\begin{array}{c}\text { Mass loss of anode } \\
(\mathrm{mg})\end{array}$ & 5,25 & 5,77 & 8,67 & 9,32 & 14,7 & 16,33 \\
\hline $\begin{array}{c}\text { Mass gain of } \\
\text { cathode (mg) }\end{array}$ & 0,23 & 0,91 & 1,95 & 5,21 & 6,83 & 8,63 \\
\hline $\begin{array}{c}\text { Mass transfer } \\
\text { coefficient }\end{array}$ & 0,04 & 0,16 & 0,22 & 0,56 & 0,48 & 0,53 \\
\hline $\begin{array}{c}\text { Surface roughness } \\
(\mu \mathrm{m})\end{array}$ & 4,63 & 9,59 & 10,31 & 13,59 & 17,7 & 17,75 \\
\hline $\begin{array}{c}\text { Recommended } \\
\text { number of layers }\end{array}$ & 3 & 2 & $2-1$ & 1 & 1 & 1 \\
\hline $\begin{array}{c}\text { Coating thickness } \\
\text { till to failure }(\mu \mathrm{m})\end{array}$ & $50 \pm 20$ & $50 \pm 40$ & $60 \pm 40$ & $65 \pm 45$ & $100 \pm 80$ & $110 \pm 105$ \\
\hline
\end{tabular}

Table 5. Some parameters of processing. Pulse amplitude is $800 \mathrm{~A}$ 


\begin{tabular}{|c|c|c|c|c|c|}
\hline $\begin{array}{c}\text { Pulse } \\
\text { duration }(\mu \mathrm{s})\end{array}$ & 300 & 400 & 600 & 800 & 1000 \\
\hline $\begin{array}{c}\text { Pulse } \\
\text { energy }(\mathrm{J})\end{array}$ & 3,02 & 4,54 & 7,87 & 11,33 & 14,52 \\
\hline $\begin{array}{c}\text { Frequency } \\
(\mathrm{Hz})\end{array}$ & 17 & 11 & 6 & 4 & 3 \\
\hline $\begin{array}{c}\text { Processing } \\
\text { electricity (C) }\end{array}$ & 3,009 & 2,937 & 2,772 & 2,668 & 2,562 \\
\hline $\begin{array}{c}\text { Time } \mathrm{t}_{1} \text { to } \\
\text { scan 1 } \mathrm{cm}^{2}(\mathrm{sec})\end{array}$ & 25 & 20 & 20 & 20 & 20 \\
\hline $\begin{array}{c}\text { Mass loss of anode } \\
(\mathrm{mg})\end{array}$ & 5,06 & 5,33 & 8,65 & 11,87 & 19,41 \\
\hline $\begin{array}{c}\text { Mass gain of } \\
\text { cathode (mg) }\end{array}$ & 0,88 & 0,73 & 2,8 & 4,6 & 7,2 \\
\hline $\begin{array}{c}\text { Mass transfer } \\
\text { coefficient }\end{array}$ & 0,17 & 0,14 & 0,32 & 0,39 & 0,37 \\
\hline $\begin{array}{c}\text { Surface roughness } \\
(\mu \mathrm{m})\end{array}$ & 5,49 & 8,28 & 14,84 & 16,38 & 17,62 \\
\hline $\begin{array}{c}\text { Recommended } \\
\text { number of layers }\end{array}$ & 3 & $2-1$ & 1 & 1 & 1 \\
\hline $\begin{array}{c}\text { Coating thickness } \\
\text { till to failure }(\mu \mathrm{m})\end{array}$ & $55 \pm 45$ & $60 \pm 45$ & $65 \pm 50$ & $100 \pm 85$ & $100 \pm 100$ \\
\hline
\end{tabular}

Table 6. Some parameters of processing. Pulse amplitude is $1000 \mathrm{~A}$

The experimental results obtained under the condition of constant pulse amplitude and increasing pulse duration were given in Tables 1-6. As mentioned previously, processing electricity was kept constant at 3 Coulomb for all experiments. Since pulse amplitude was constant, pulse energy was increased by increasing pulse duration. Main objective of this investigation was to increase both mass loss of treating electrode and mass gain of the substrate, in turn coating thickness, especially for the first layer of deposition. Higher pulse energy causes higher mass gain of substrate and shorter processing time till to the beginning of mass loss (destruction of deposit already formed). Despite the mass gained from treating electrode, a decrease in weight of the substrate was observed for pulse duration of $4000 \mu \mathrm{s}$ in case of 100 A pulse amplitude after 1.5 minutes of processing (Fig. 2), for pulse duration of $2000 \mu$ s in case of 200 A pulse amplitude after 1.5 minute processing (Fig. 3) and for pulse duration of $400 \mu \mathrm{s}$ in case of $400 \mathrm{~A}$ pulse amplitude after 2.0 minute processing (Fig. 4). Further increase of pulse duration caused substrate to start to lose mass in shorter processing time.

Upon further alloying, the mass loss, in other words, the destruction of layer already formed intensifies and the destruction could reach substrate by removing already formed layer totally. In Fig. 8, cross-sectional micrograph of a coating was given as an example in order to show the beginning of destruction. Part of the specimen was not purposely alloyed (see the upper part of micrograph) in order to be able to compare the level of coating thickness and depth of destruction with the original level of the surface.

In case of $100 \mathrm{~A}$ pulse amplitude, during alloying with pulse duration longer than $200 \mu \mathrm{s}$, erosion of molten pool on substrate was observed from the very beginning of alloying due to the presence intensive gas dynamics phenomena in plasma channel. This type of erosion was named "washing away" which is the mass lost by substrate (Rybalko et al., 2008). 


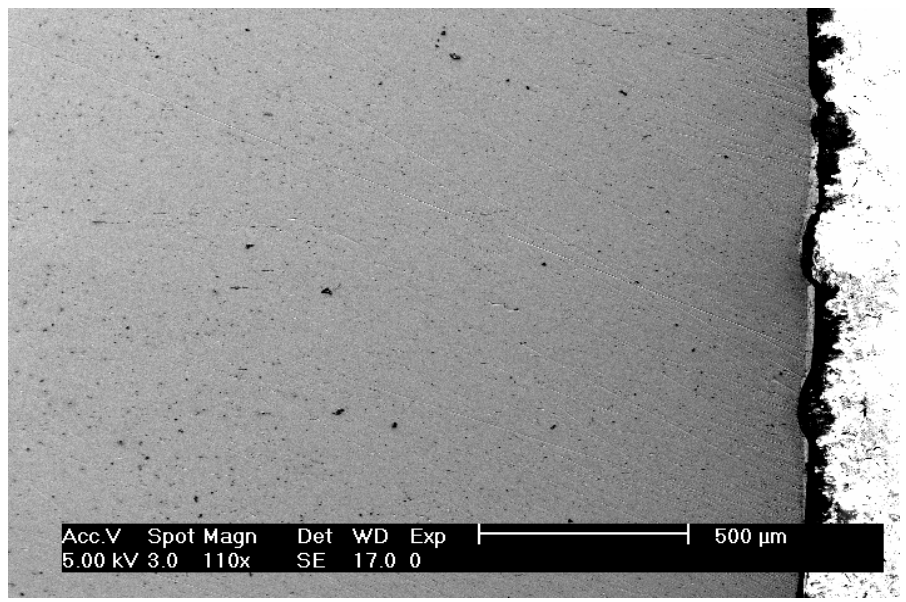

Fig. 8. Cross-sectional micrograph of a coating showing the locations of failure

Therefore, the change in weight of the substrate is the difference between the liquid mass received from treating electrode and the liquid mass loss due to washing away of its molten pool at the beginning of a spark discharge. Intensive washing away was observed with pulse durations of $400 \mu \mathrm{s}$ in case of $100 \mathrm{~A}$ pulse amplitude, $200 \mu \mathrm{s}$ in case $200 \mathrm{~A}$ pulse amplitude, and $200 \mu \mathrm{s}$ in case of 400 A pulse amplitude. The micrograph (Fig. 9) shows that, the liquid material ejected from treating electrode filled up the substrate pool after washing away was completed.

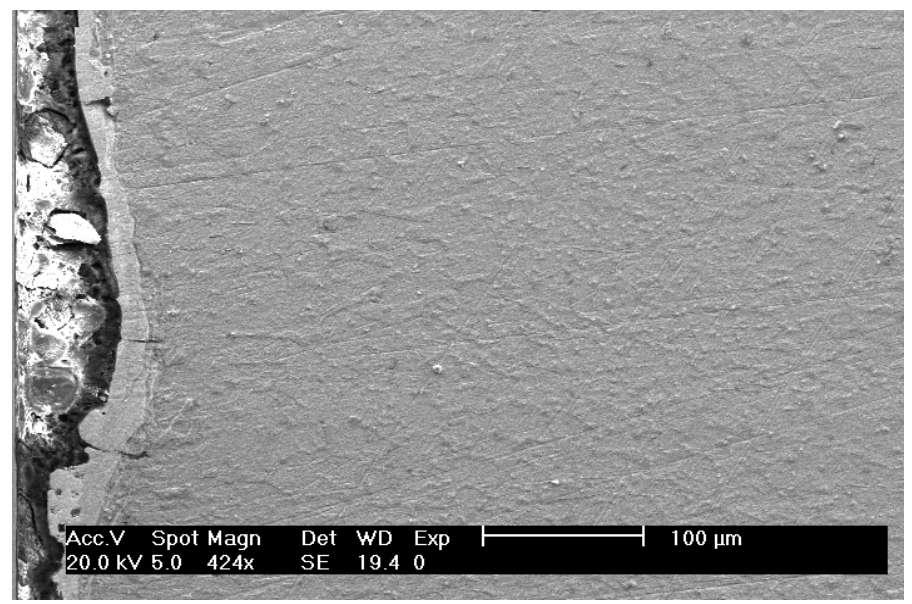

Fig. 9. Cross-sectional micrograph of a coating showing the location of pool on substrate

For the pulse duration of $1000 \mu$ s in case 100 A pulse amplitude, the morphology of coating changed essentially. There were pores at the upper part of the layer that were formed by superficial boiling of the transferred material. Pulse durations more than $1000 \mu$ s caused the formation of large pores not only at the surface, but also inside the deposited layer. Boiling was caused by significant amount of heat transferred to the substrate from overheated 
liquid material of the treating electrode. It is obvious that such a large volume of mass transfer warms up the substrate. For pulse duration of $4000 \mu \mathrm{s}$, superficial boiling in deposited layer was all over and pores were close to the substrate (Fig. 10). As in the case of pulse duration of $1000 \mu \mathrm{s}$, the essential role in forming a layer was determined by gas dynamics in plasma channel.

Alloying in case of 200 A pulse amplitude was similar to the alloying in case of $100 \mathrm{~A}$. Examination of the morphology and cross-section of deposited layer showed that high quality deposit was limited by pulse duration of less than $400 \mu$ s.

It is noticed that in case of $400 \mathrm{~A}$ pulse amplitude, alloying till pulse duration of $300 \mu \mathrm{s}$ could be carried out without any destruction. However, mass transfer was low. The alloying by pulse duration above $300 \mu$ s was already characterized by a decrease in mass transfer that marks the beginning of destruction of layer formed already. Further increase in pulse durations leads to the evaporation of substrate through cavities in coating.

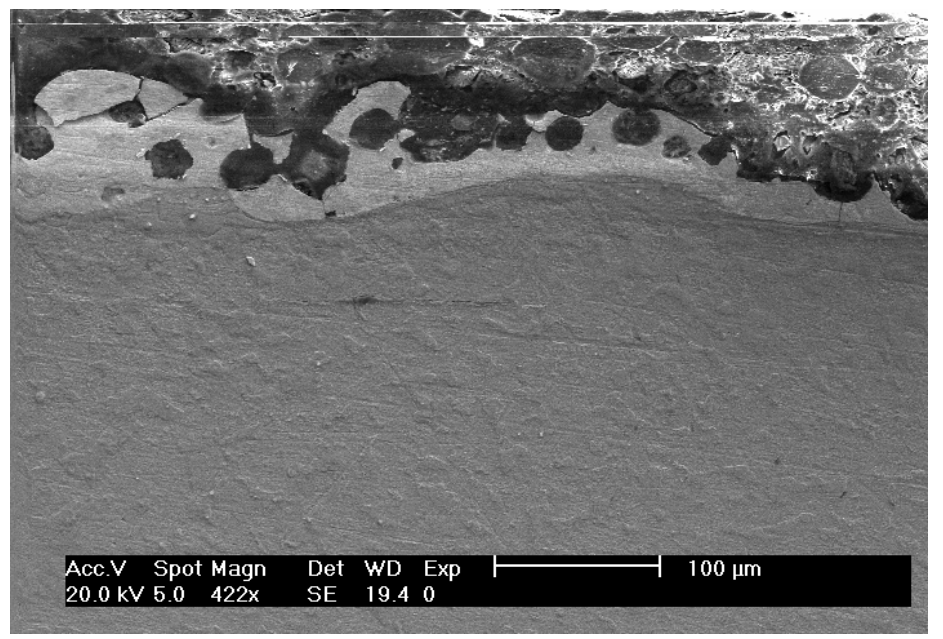

Fig. 10. Cross-sectional micrograph of a coating. Pulse duration is $4000 \mu \mathrm{s}$. Pulse energy is $6.8 \mathrm{~J}$

Morphology of the deposited layer was different than that of alloying by pulse amplitudes of $200 \mathrm{~A}$ and $100 \mathrm{~A}$. This is due to the overheating of substrate at the interface of plasma channel and substrate. The longer the pulse durations, the higher the overheating. Concerning deposition under these conditions, the following could be assumed. The plasma channel of the discharge overheats the deposited layer. Its melting temperature is already higher than that of substrate and, as a results, molten zones of substrate form under deposited layer. Molten zones flow out through cavities in coating. After reaching the surface the molten substrate material covers and mixes with the erosive mass transferred from the treating electrode. The mixed mass solidifies on the surface of coating formed earlier. This would probably explain the presence of low microhardness at the coating surface, and also increase its surface roughness. In case of ESA with pulse durations more than $600 \mu$ s (pulse amplitude is $400 \mathrm{~A}$ ), the process was characterized by an increase in the area of splash. Thus, rate of the first layer deposition increases, but the rate of thickness build up of this layer decreases. 
In case of alloying with pulse amplitudes of $100 \mathrm{~A}, 200 \mathrm{~A}$ and $400 \mathrm{~A}$, if pulse duration is above $1000 \mu \mathrm{s}$, porous foam-like coatings were obtained. Since the amounts of pulse energies were significantly different for these three cases, one could conclude that the length of pulse duration is the reason of this kind of coating.

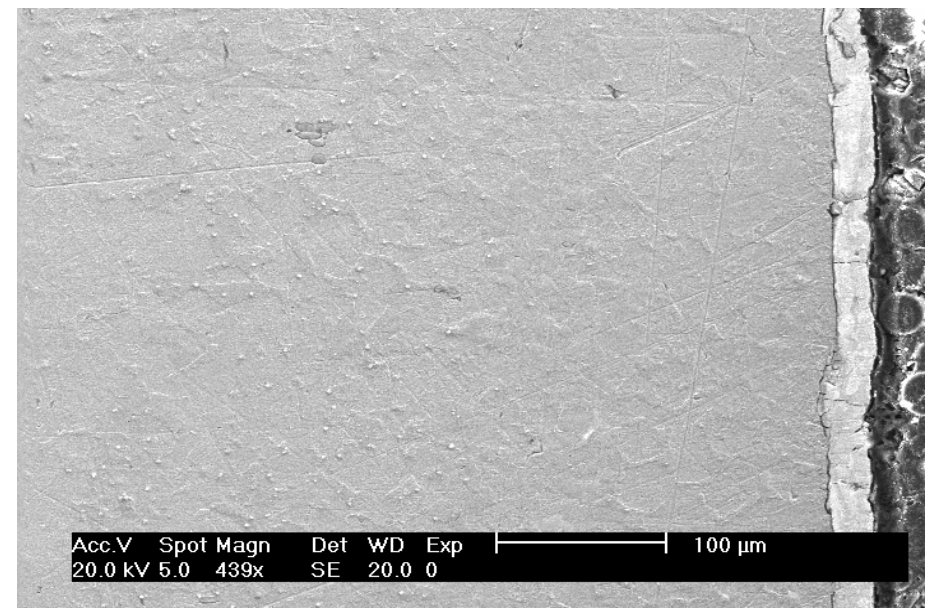

Fig. 11. Cross-sectional micrograph of a coating. Pulse duration is $600 \mu \mathrm{s}$. Pulse energy is $1.1 \mathrm{~J}$

Alloying with the pulse amplitude of 100 A leads to high quality coatings with an average thickness of 10-35 $\mu$ s for the pulse duration up to $1000 \mu$ s (Fig. 11). Increasing pulse duration was accompanied by an increase in non-uniformity of thickness. For manual alloying with pulse amplitudes of $200 \mathrm{~A}$ and $400 \mathrm{~A}$, pulse duration more than $400 \mu$ s would not be recommended. Below $400 \mu \mathrm{s}$, it is possible to obtain a high quality coating with an average thickness of 50 microns (200 A) and 65 microns (400 A) till the beginning of destruction (Fig 12). ESA with longer pulse durations allows only one layer of scanning without destruction. The thickness of a spot due to an individual discharge could be as much as 120 microns at the center and lower at the edges. In this condition, in order to obtain high coating thickness the thinner edges of the neighboring splashes should be overlapped during the deposition process. Therefore, it is necessary to carry out process with use of an automated installation. Scanning rate of automated installation could be adjusted to provide partial overlapping of subsequent splashes.

In case of alloying with $600 \mathrm{~A}$ pulse amplitude, if the pulse durations were more than $300 \mu \mathrm{s}$, intensive substrate overheating occurred at the plasma channel-substrate interface. When the pulse durations were above $400 \mu \mathrm{s}$, substrate evaporated during deposition of the second layer. ESA process was accompanied by unusually big plasma flame escaping from the interelectrode zone during spark discharge. The size of plasma flame was essentially wider than the cross-sectional area of treating electrode. Layer formation by spark discharges with pulse durations of $1000 \mu \mathrm{s}$, was characterized by the occurrence of large pores including open pores at the surface. Alloying with pulse duration of $2000 \mu$ s (pulse energy is 18,78 J) was tried. However, due to sticking of electrodes, alloying was not possible.

In case of processing with pulse amplitude of $800 \mathrm{~A}$ and pulse duration of $600 \mu$ s, electrodes stuck to each other. Moreover, during processing with pulse duration of $800 \mu \mathrm{s}$, strong 
radiation due to intensive evaporation in substrate was present (after scanning of the first layer), and use of pulse duration of $1000 \mu$ s formed a deposition with large pores. Alloying with pulse durations higher than $1000 \mu$ s could not been achieved due to strong sticking during the deposition of first layer.

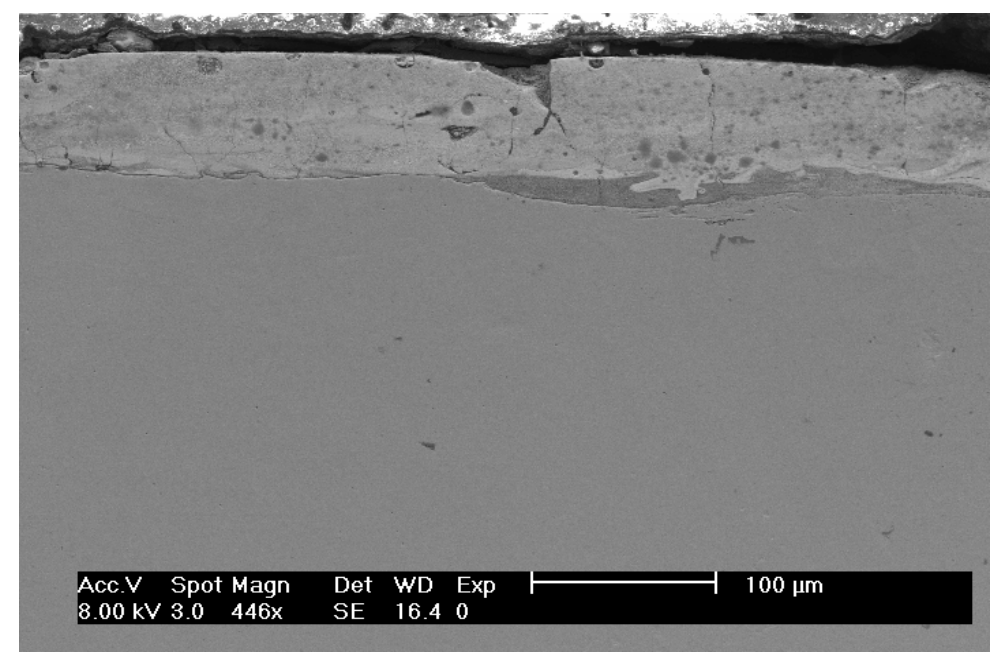

Fig. 12. Cross-sectional micrograph of a coating. Pulse duration is $400 \mu \mathrm{s}$. Pulse amplitude is $400 \mathrm{~A}$. Pulse energy is $2.39 \mathrm{~J}$

In case of alloying with 1000 A pulse amplitude, when the pulse duration was $300 \mu \mathrm{s}$, erosive mass of electrodes was scattered all over because of intensive gas dynamics phenomena in plasma channel. Therefore, as same as the processing with long pulse duration, the coefficient of mass transfer was low and roughness of deposition was high because of the big differences in thickness in an individual spot. The average thickness of deposit was $55 \pm 40$ micron. Alloying was carried out without sticking of electrodes and oxidation of surface.

When the pulse duration was more than $300 \mu \mathrm{s}$, substrate evaporation began right after coating of the first layer and an oxide film formed on the surface of deposit. Above $800 \mu \mathrm{s}$ electrodes stuck to each other and above $1000 \mu$ s formation of large pores was all over. Coating thickness varied between $5 \mu$ s and $200 \mu \mathrm{s}$.

In case of alloying with pulse amplitudes of $600 \mathrm{~A}, 800 \mathrm{~A}$ and $1000 \mathrm{~A}$, a porous deposition like foam was obtained by the application of $1000 \mu$ s pulse duration. Since, pulse energies were significantly different from each other for these three cases, pulse duration could be responsible for the formation of similar kind of porous formation.

The analysis of the experimental results shows that, the occurrence of destruction correlates with the time of decrease in mass transfer coefficient, calculated from data, given in Tables 4,5 and 6. Proceeding from the data of the beginning of decrease in mass transfer coefficient, number of probable deposited layers (number of scanning), at which coating destruction will not be observed, was determined and recommended in these tables. Investigation shows that under the experimental conditions given above, it is possible to deposit only one layer above the pulse duration of $400 \mu \mathrm{s}$. 
In Tables 4, 5 and 6, average coating thickness obtained under recommended number of scanning is given. The analysis of this data shows that if pulse duration increases, the average thickness increases, in spite of the fact, that the number of recommended layers for alloying decreases.

In case, if it is necessary to deposit only one layer, irregular coating (non uniform thickness) is inevitable. For example, ESA with pulse duration of $800 \mu$ s and pulse amplitude of 1000 A, the minimum thickness of the deposited spot due to a single spark discharge was 10 microns at the edge and 200 microns at the center. Thus, a layer of $1 \mathrm{~cm}^{2}$ area could be formed by only 60 spark discharges: 3 pulses per second for a total processing of 20 seconds (Table 6). Morphology of coating is similar to the one illustrated in Fig. 13 (cross-sectional micrograph)

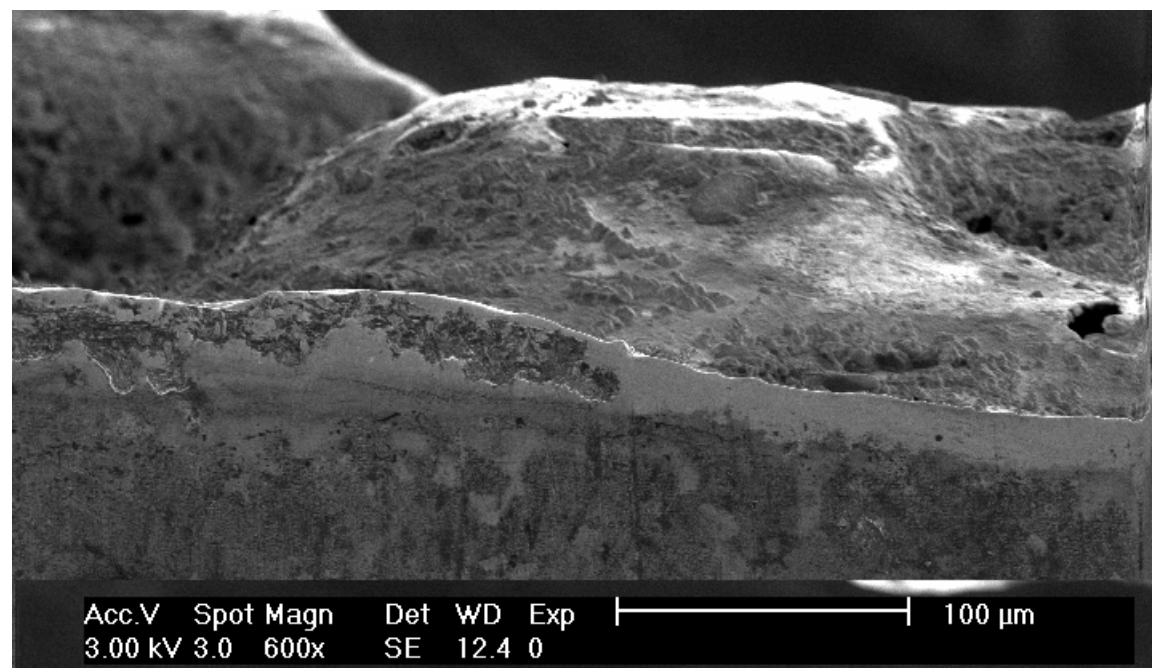

Fig. 13. A typical view of cross-section and surface of a coating could be obtained with high energy pulses. Pulse amplitudes and pulse durations could be from $600 \mathrm{~A}$ to $1000 \mathrm{~A}$ and 400 to $1000 \mu$ s respectively

\section{General results of electrospark alloying}

Regarding the experimental results, following generalizations could be made, which essentially could change the approach to the ESA technology (Ribalko et al., 2005; Ribalko \& Sahin, 2006). Nonlinear decrease in erosion of treating electrode during alloying of steel specimens after the first layer deposition was a fact. Thus, it is possible to ascertain that an additivity principle observed by B.R. Lazarenko in case of electroerosive dimensional machining, is not true in case of ESA after first layer of deposition (Ribalko et al., 2004b). The additivity principle is the stationary anodic erosion when the discharge energy between electrodes is constant. The observed decrease in anodic mass change in case of ESA was due to the decrease in power of cathodic stream, in turn, due to the change in surface properties of the substrate after alloying of its surface with treating electrode. The cathodic stream conduces to the anodic erosion. 
As it was shown experimentally, the phenomenon of coating destruction by its evaporation occurred during alloying in all ranges of pulse parameters investigated. Thus, to obtain high quality depositions, it is necessary to limit the processing time by the moment of the signs, indicating destruction of the deposited layer. The beginning of coating destruction could be determined by some features of ESA, namely: when mass loss of treating electrode ceases down to a minimum stable level, when mass gain of substrate becomes zero or even negative and the moment of a sharp decrease in mass transfer coefficient

Most precisely, the beginning of coating destruction could be defined as the moment of sharp decrease in mass transfer coefficient, which is the ratio between the mass gain of substrate to the corresponding mass loss of treating electrode between two successive measurements. The decision could be considered as a criterion to end the process.

The analysis of experimental results indicates that the number of superimposed layers prior to the beginning of coating failure, for the investigated range of pulse energies, depends on pulse energy and it could be between 1 and 3 (the latest one is for low pulse energy) (Fig. 14). A single-valued dependence of the number of these layers to the amount of pulse energy was not observed. The same number of layers could be obtained by the employment of different pulse energies which depend on pulse amplitude and pulse duration. As an example, for 3 layers of deposition, either a pulse amplitude of $400 \mathrm{~A}$ (pulse energy not more than $0.3 \mathrm{~J}$ ), or a pulse amplitude of $800 \mathrm{~A}$ (pulse energy not more than $1.5 \mathrm{~J}$ ) or pulse amplitude of 1000 A (pulse energy not more than $3 \mathrm{~J}$ ) could be employed. It should be noticed that, although there is a ten fold increase in pulse energy, the maximum number of deposited layers prior to fracture does not change. This behavior was explained as follows. Despite of the constant amount of electricity for the ESA processing (3 Coulomb), deposition time of the first layer strongly varies, and it was, for example, 20 seconds for a high pulse energy case and 70 seconds for a low pulse energy case. Examination of the surface morphology of coatings shows that size, e.g. average diameter, of the solidified splashes due to mass transferred by a single pulse for the each energy significantly varies. For the low pulse energy of $0.032 \mathrm{~J} \mathrm{(100} \mathrm{A,} 25 \mu \mathrm{s}$ ) the time to scan the substrate area of $1 \mathrm{~cm}^{2}$ requires 80650 pulses (then the average splash area as a result of each spark discharge is roughly $\left.0.00124 \mathrm{~mm}^{2}\right)$ and for the high pulse energy of $9.47 \mathrm{~J}(800 \mathrm{~A}, 800 \mu \mathrm{s})$, the same area was totally scanned by the application of only 125 pulses (thus the average splash area is nearly $0.8 \mathrm{~mm}^{2}$ per pulse). That is, although pulse energy was increased 259 times, the average splash area was increased 645 times. Therefore, the growth of splash size is not directly proportional to the increase in pulse energy.

The erosive processes on treating electrode and substrate are determined not only by the electrical parameters of discharge and the chemical properties of the electrodes, but also, substantially by the rate of heat flow received by the electrodes (Namitokov, 1978; Butkevich et al., 1978). The amount of heat which could cause evaporation of substrate under the first layer of coating is not reached by the employment of long duration pulses, as in the case of pulses which have same energy but shorter duration. To reach dense heat flow in electrodes high enough to cause same kind of fracture, it is necessary to raise the energy of a long duration pulse by increasing its amplitude.

Since the number of superimposed layers prior to beginning the fracture of coating is limited, the amount of mass loss of the treating electrode and mass gain of the substrate are also limited. It is of interest to determine the amount of mass transfer, in turn coating thickness, quantitatively till fracture. As mentioned previously, it is a fact that the 


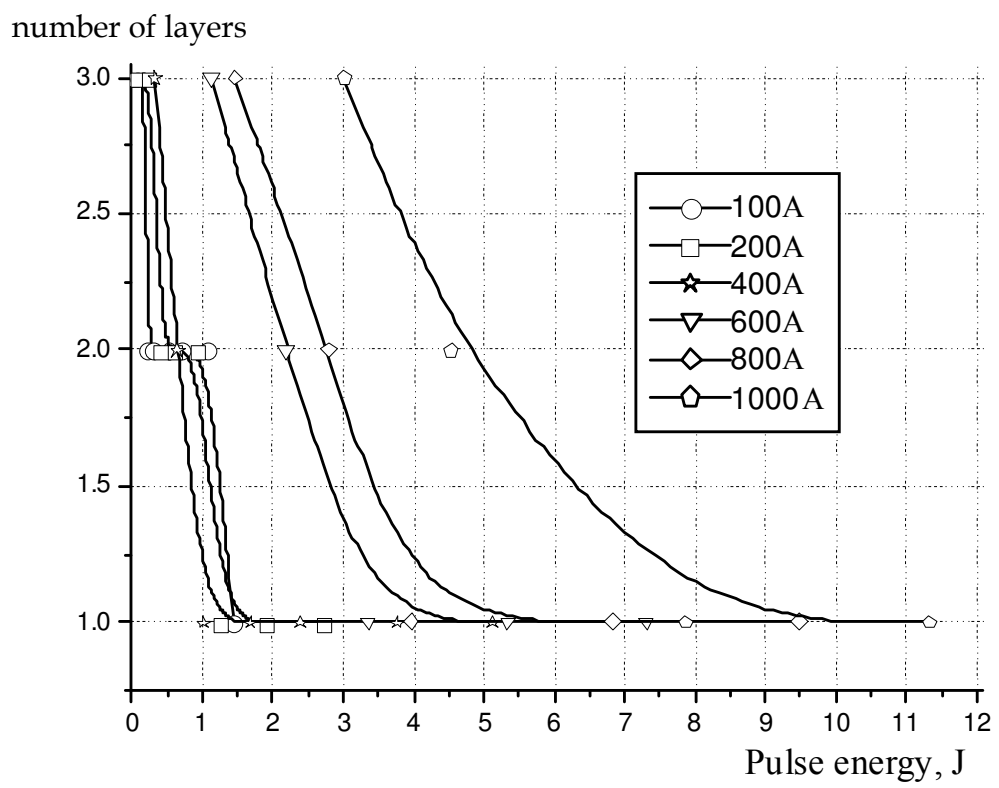

Fig. 14. The relationship between pulse energy and number of layers which could be superimposed without fracture of coating

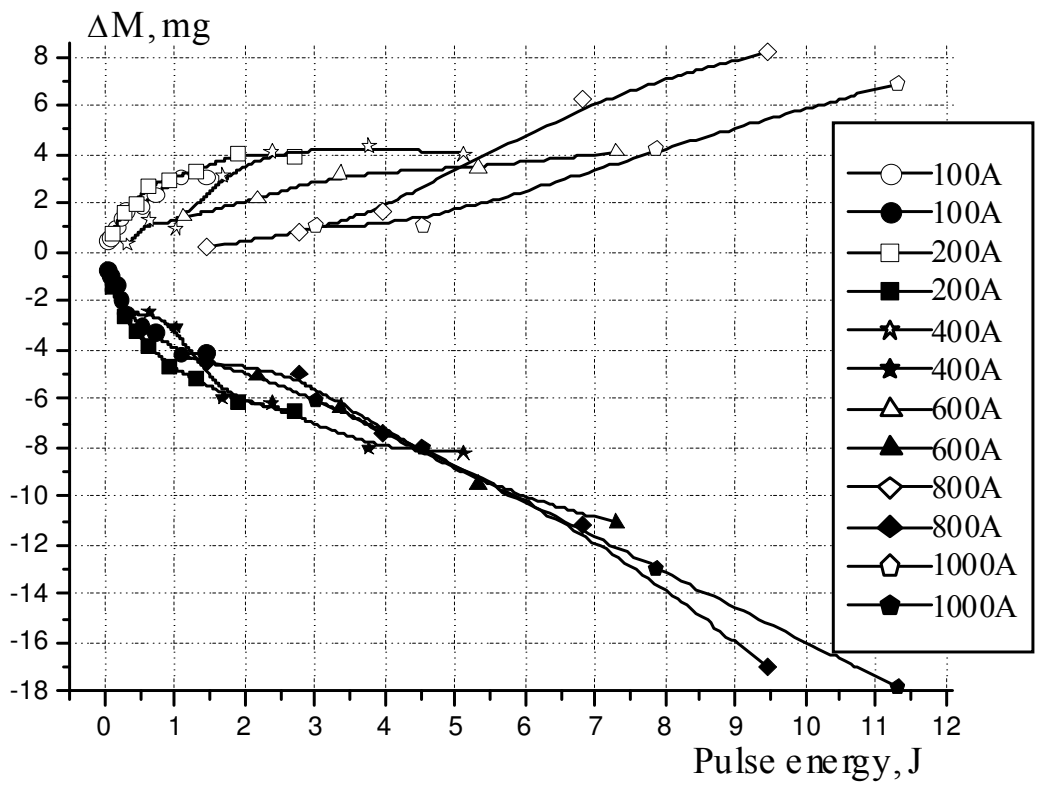

Fig. 15. Mass loss of treating electrode (solid dots) and mass gain of substrate as a function of pulse energy. Processing time is $30 \mathrm{~s}$ 
experimental conditions of ESA (processing parameters e.g. properties of electrodes, medium and electrical pulse parameters), are the same only for the deposition of first layer. Therefore, the experimental data could be compared for the first layer of depositions only.

For alloying time of 30 seconds, i.e. first layer of deposition, the change in mass of electrodes as a function of pulse energy was given in Fig. 15. Amplitudes of pulses were marked on the figure as well. The data were taken from Tables 1-6. As it is seen, the relation between the mass loss of treating electrode and pulse energy is not linear. For example, the mass loss of treating electrode to the pulse energy ratio is about $10.0-12.0 \mathrm{mg} / \mathrm{J}$ for pulse energy of $0.25 \mathrm{~J}$. This ratio is only $1.42 \mathrm{mg} / \mathrm{J}$ for the pulse energy of $1.0 \mathrm{~J}$ and it does not practically vary further with increasing energy. The nonlinearity of the treating electrode mass loss is originated from the decreasing rate of heat flow density in electrodes.

Apparently, the difference between these two ratios is significant. This result could be interpreted as; on the one hand, to use energy effectively, pulses with low energy should be used for processing, on the other hand, to obtain considerably thick coating, i.e. high erosion of treating electrode, it is necessary to use pulses with high energy under the condition of single layer scanning.

Various combinations of pulse energy components, pulse amplitude and pulse duration did not produce a wide scatter in the values of mass loss of the treating electrode (Fig. 15). The voltage drop at the moment of spark discharge which is a requirement of ESA was constant at around $17 \mathrm{~V}$ for the present electrode couple (WC92-Co8 - steel 35). Using the experimental data about mass loss of treating electrode versus pulse energy till $5 \mathrm{~J}$, an empirical relation given below was derived. For a given energy, the corresponding values of mass loss of treating electrode taken from Fig. 15, were averaged.

$$
\Delta \mathrm{M}_{\mathrm{a}}=\left(\Delta \mathrm{M}_{\mathrm{a}, \mathrm{sp}} \cdot \mathrm{C} \cdot \mathrm{t}\right) \mathrm{mg}
$$

where, $\Delta \mathrm{M}_{\mathrm{a}, \text { sp. }}=\left(0.0089+0.0555 \mathrm{~W}-0.0243 \mathrm{~W}^{2}+0.0054 \mathrm{~W}^{3}-0.0004 \mathrm{~W}^{4}\right)$ is the specific value of the mass loss of treating electrode for 1 Coulomb of electricity spent during 1 second alloying $(\mathrm{mg} / \mathrm{C} \cdot \mathrm{s}) ; \mathrm{C}$ is the amount of electricity of ESA processing (Coulomb); $\mathrm{t}$ is the time for the first layer deposition (s); $\mathrm{W}$ is the amount of pulse energy (J). The calculated curve and experimental average curve (solid dots) of the mass loss of the treating electrode are given in Fig. 16 for a 30 seconds of alloying by spending 3 Coulomb of electricity.

However, for a given pulse energy, the mass gain of the substrate shows a wide scattering depending on the pulse amplitude (Fig. 15). For example, for a pulse energy of $1.5 \mathrm{~J}$ which could be obtained by the application of pulse amplitudes of $200 \mathrm{~A}, 400 \mathrm{~A}, 600 \mathrm{~A}$ and $800 \mathrm{~A}$, the mass gains of substrate were $3.5 \mathrm{mg}, 2.5 \mathrm{mg}, 1.7 \mathrm{mg}$ and $0.25 \mathrm{mg}$, respectively. The difference in mass gained by substrate is because of two concurrent mass actions. These are the mass transferred from treating electrode and the mass loss due to washing away of molten pool of substrate spot caused by the intensive gas dynamics phenomena in plasma channel at the beginning of each spark discharge. In the case of processing with high pulse amplitude, due to larger material washed away, the mass loss of substrate would be expected to be more. However, cross sectional thickness measurements show that the thicknesses of coatings were close to each other despite the large differences in the amount of mass gain (14 times). This shows that the mass gained by substrates were almost the same despite the differences in pulse amplitudes. So, the amount of mass gained by substrate could be calculated by a simple relation, if the effect of washing away is negligible: 


$$
\Delta \mathrm{M}_{\mathrm{c}}=\left(\mathrm{k}_{\mathrm{tf}} \cdot \Delta \mathrm{M}_{\mathrm{a}}\right) \mathrm{mg}
$$

where, the mass transfer coefficient, $\mathrm{k}_{\mathrm{tt}}$, is equal to 0.74-0.60 (less for higher pulse amplitude). The mass transfer coefficients given in Fig. 28 for the pulse amplitude beyond 200 A could not be used in Eq. 2, because the amount of mass loss of substrate due to washing away was not taken into account for the calculation of $\mathrm{k}_{\mathrm{tf}}$.

Under this circumstance, the mass transfer coefficient should carefully be used to estimate the efficiency of mass transfer from treating electrodes to substrates. The following is an attempt to explain this point in detail.

The mass transfer coefficients as a function of pulse energy for the first layer of deposition were given in Fig. 17. The mass transfer coefficients corresponding to the short pulse durations were minimum for all pulse amplitudes ranging from $100 \mathrm{~A}$ to $1000 \mathrm{~A}$. Since the substrate material was washed away due to the gas dynamics process at the beginning of a pulse, among these, the highest mass transfer coefficient belongs to smallest pulse amplitude which could not wash away molten substrate material.

The increase in pulse energy by means of increasing pulse duration which increases the mass transfer coefficient, because the mass gained by substrate from treating electrode is probably higher than the mass loss of original substrate as a result of washing away that occurs mainly at the beginning of the pulse. The amount of mass washed away during deposition of the first layer is not simple to measure, therefore the procedure to estimate the efficiency of mass transfer from treating electrode to substrate with the help of mass transfer coefficients is not quite correct.

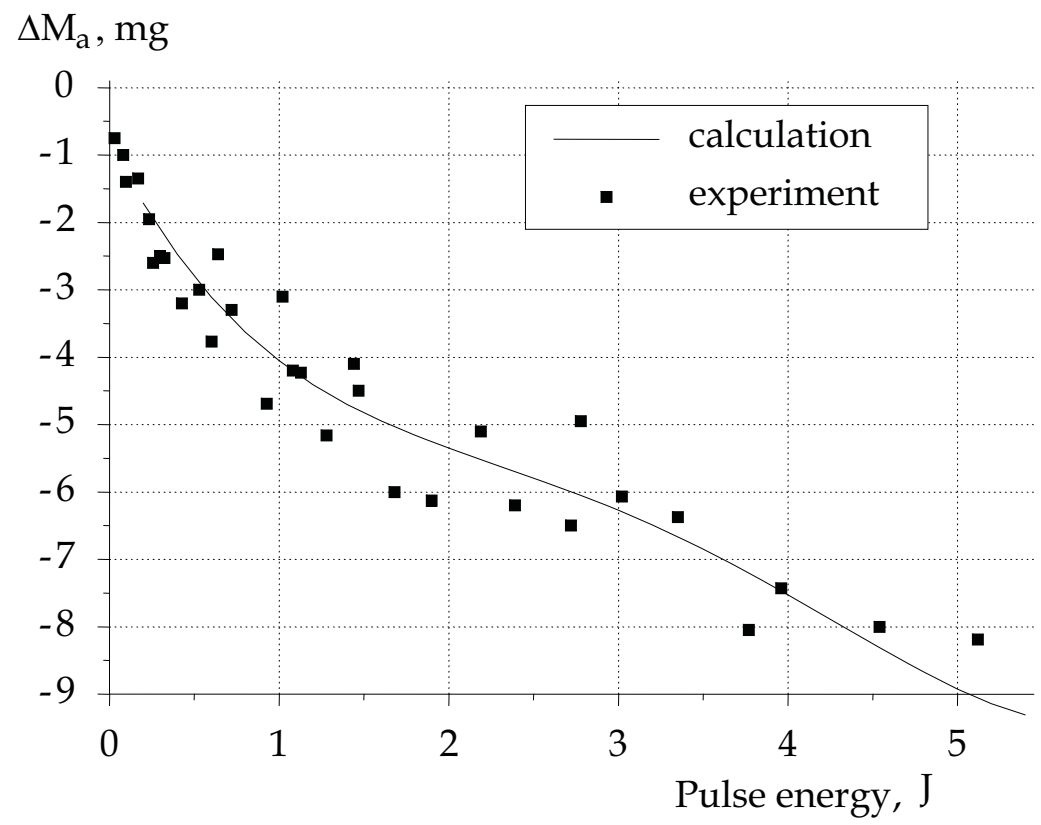

Fig. 16. Calculated curve and experimental data of mass loss of treating electrode as a function of pulse energy 


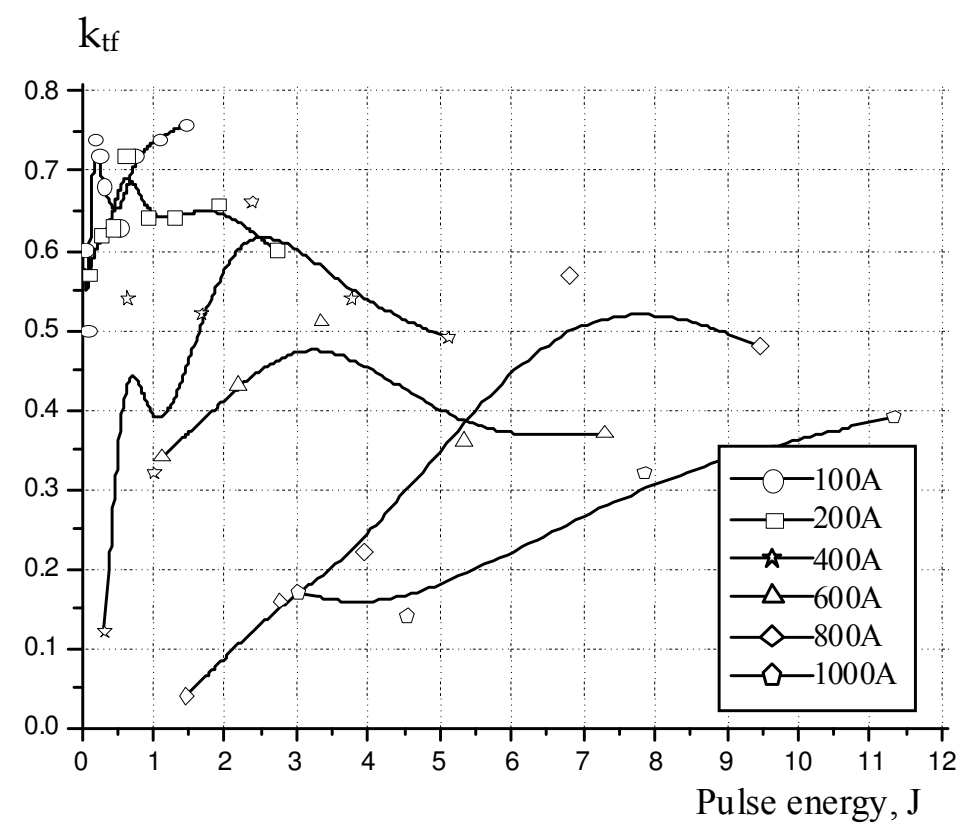

Fig. 17. Mass transfer coefficient as a function of pulse energy. Processing time is $30 \mathrm{~s}$

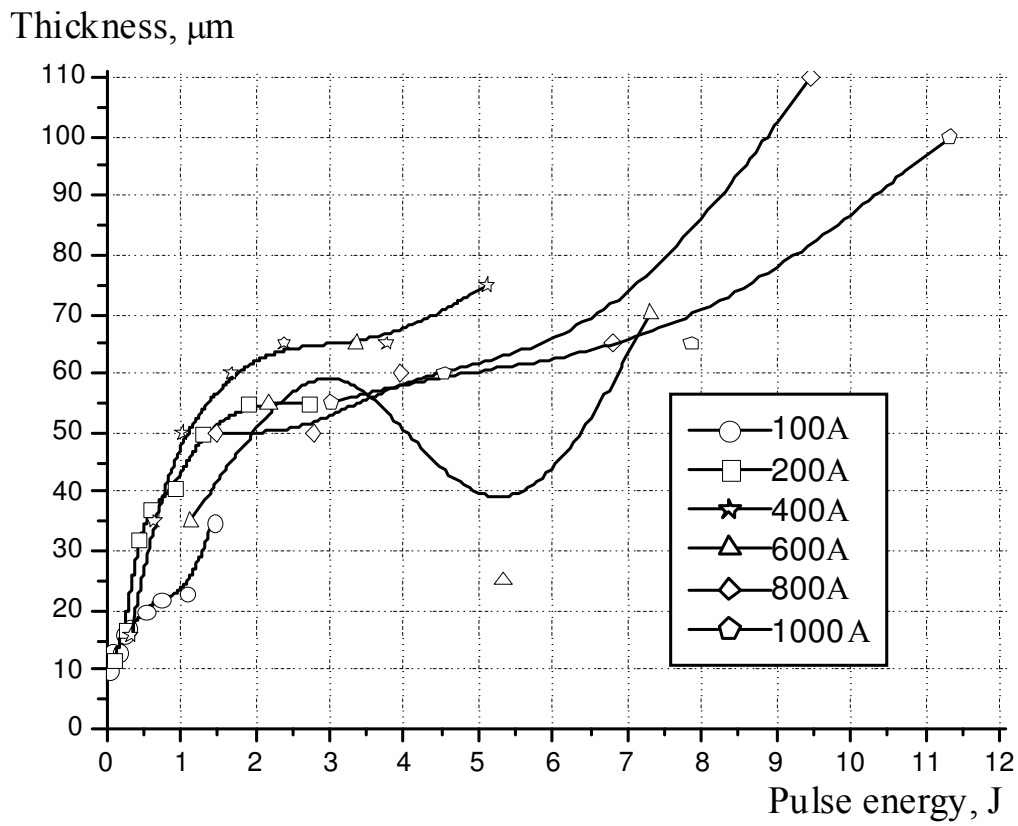

Fig. 18. Average coating thickness as a function of pulses energy 
One might estimate the range of coating thicknesses that could be obtained under the necessary restrictions for the number of superimposed layers. That is, substrates should be alloyed according to the condition given in Fig. 14. The average thickness of coating as a function of pulse energy was given in Fig. 18. For any chosen pulse amplitude, the coating thickness increases with increasing pulse energy, especially, for the low pulse energy range the rate of increase was the highest. Upon further increase of pulse energy, above $1 \mathrm{~J}$, the growth of coating thickness levels off, that correlates in the course of mass loss of treating electrode as shown in Fig. 15.

\section{General conclusion}

The failure of coating during processing was observed for the entire range of pulse parameters that were employed. In order to save already deposited layer, it is necessary to limit the processing time by the beginning of its failure.

As mentioned previously, when chemical composition of the substrate surface becomes as same as that of treating electrode after some deposition, the mass transfer from treating electrode to substrate ceases down. This is a limitation on coating thickness in ESA technology. Therefore, pulse energy was increased in order to increase the mass loss of treating electrode and its transfer to the substrate. However, it was experimentally found out that the other limitation of mass transfer, in turn limitation on layer thickness is the destruction of already deposited layer during processing. This was due to local evaporation of materials underneath the outer surface of deposit. Evaporation was due to the heat provided locally by spark discharges of high energy pulses.

Most of the molten material at the tip of the treating electrode could not be ejected out. Part of the ejected molten mass could be transferred to substrate and the rest is wasted. The ejected mass, so the transferred mass, could be increased by the employment of pulse groups instead of employing individual pulses (Rybalko et al., 1998; Ribalko et al., 2006, 2008). Mass transferred to the substrate could also be increased by the choice of an optimum scanning rate of the treating electrode. Because cross-section of a single deposit has very big difference in thickness (if the mass transfer time is long), the spot has higher thickness in center. For a continuous coating, the subsequent spot should partially overlap with previous spot. But, continuity of coating essentially depends on the experience of the operator. Thus, a continuous coating with uniform thickness demands compulsory automated spot deposition system with pre-determined rate of speed to provide necessary level of spot overlapping. Consequently, the non uniformity in coating thickness could be lowered and average coating thickness, that is mass transfer, would essentially be increased.

\section{References}

Butkevich, G.V.; Belkin, G.S.; Vedeshenkov, N.A. \& Javoronkov, M.A. (1978). Electrical erosion of heawy-current contacts, Energy. Moscow, 256 p. (in Russian)

Lazarenko, B.R. (1951). Method of metal surfaces deposition. The USSR Patent №89933. Unveil in Bulletin of Invention in USSR (in Russian)

Lazarenko, N.I. (1976). Electrospark alloying of metal surfaces. In: Mechanical Engineering, Vanity press, Moscow (in Russian) 
Lazarenko, N.I. (1957). Change of initial properties of a cathode surface under the electric pulses, proceeding in the gas environment. In: Electrospark Processing of CurrentCarrying Materials, Publication 1. Vanity Press, Academy of Science of the USSR, Moscow, pp. 70-94 (in Russian)

Namitokov, K.K. (1978). Electroerosion phenomenon, Energy. Moscow, 456p. (in Russian).

Ribalko, A.V.; Siminel, A.V. \& Sahin, O. (2004a). Electrospark processing by hard-alloy treating electrode under the conditions of unconventional pulse parameters. 2. Range of pulse duration (50-4000) $\mu$ s at amplitude of current 200 and 400A. Metal working, Vol.2, No.20, pp. 6-11 (in Russian)

Ribalko, A.V.; Siminel, A.V. \& Sahin, O. (2004b). Electrospark processing by hard-alloy treating electrode under the conditions of unconventional pulse parameters. 3 . Range of pulse duration (200-1000) $\mu$ s at amplitude of current 600-1000A. Metal working, Vol.4, No.22, pp. 10-15 (in Russian)

Ribalko, A.V.; Siminel, A.V. \& Sahin, O. (2005). Electrospark processing by hard-alloy treating electrode under the conditions of unconventional pulse parameters. 4. Generalization of results. Metal working, Vol.3, No.27, pp. 21-28 (in Russian)

Ribalko, A.V. \& Sahin, O. (2006). A modern representation of the behavior of electrospark alloying of steel by hard alloy. Surface and Coatings Technology, Vol.201, No.3-4, pp.1724-1730.

Ribalko, A.V.; Korkmaz, K. \& Sahin, O. (2008). Intensification of the anodic erosion in electrospark alloying by the emploument of pulse group. Surface and Coatings Technology. Vol.202, No.15, pp. 3591-3599

Ribalko, A.V.; Siminel, A.V.; Sahin, O. \& Korkmaz, K. (2006). About possibility of anode erosion increase in electrospark alloying by pulses of invariable electric parameters. Metal working, Vol.6, No.36, pp. 45-52 (in Russian)

Rybalko, A.V.; Grichuk, D.; Ermilov, V.V. \& Mindru, D. (1998). The patent of Moldova №997. Procedeu de aliere prin electrorodare, Method of an electrospark alloying, Vol.7 (in Moldovian)

Rybalko, A.V.; Siminel, A.V. \& Sahin, O. (2003a). The Electrospark alloying by isopower current pulses with various form. Metal working, Vol.1, No.13, pp. 18-22 (in Russian)

Rybalko, A.V.; Siminel, A.V. \& Sahin, O. (2003b). Installation for an electrospark alloying of new generation. International Symposium on Electroerosive processing of materials. Moscow, Russia, April 2003 (in Russian)

Rybalko, A.V.; Siminel, A.V. \& Sahin, O. (2003c). Modern installation for an electrospark alloying. Metal working, Vol.6, No.18, pp. 38-40 (in Russian)

Rybalco, A.V.; Grichuc, D.M.; Ermilov, V.V. \& Sahin, O. (2000). Procedeu de aplicare an acoperirilor prin electrorodare (the Method of electrospark processing). Pat. №1414. Moldova (in Moldovian)

Rybalko, A.V.; Siminel, A.V. \& Sahin, O. (2003e). Dynamic of formation and destruction carbide of tungsten coverings in the course of an electrospark alloying. Metal working, Vol.4, No.16, pp. 7-10 (in Russian)

Rybalko, A.V.; Siminel A.V. \& Sahin, O. (2003d). An electrospark alloying by hardfacing treating electrode in the conditions of application of nonconventional of pulse electric parameters. 1. Change of pulse duration in a range (25-4000) $\mu$ s at the fixed current amplitude 100A. Metal working, Vol.5, No.17, pp. 10-15 
Zolotih, B.N. (1957). About the physical nature of electrospark metal processing. In: Electrospark processing of current-carrying materials, Publication 1. Vanity Press Academy of Science of the USSR, Moscow, pp.38-69 (in Russian) 


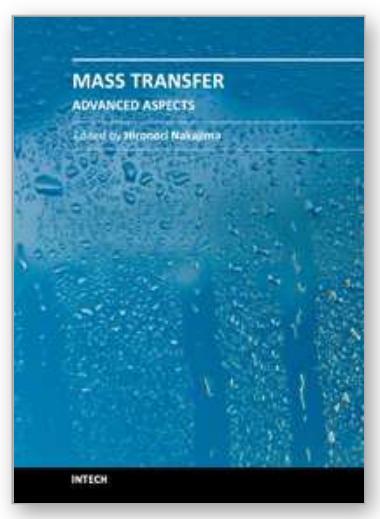

\author{
Mass Transfer - Advanced Aspects \\ Edited by Dr. Hironori Nakajima
}

ISBN 978-953-307-636-2

Hard cover, 824 pages

Publisher InTech

Published online 07, July, 2011

Published in print edition July, 2011

Our knowledge of mass transfer processes has been extended and applied to various fields of science and engineering including industrial and manufacturing processes in recent years. Since mass transfer is a primordial phenomenon, it plays a key role in the scientific researches and fields of mechanical, energy, environmental, materials, bio, and chemical engineering. In this book, energetic authors provide present advances in scientific findings and technologies, and develop new theoretical models concerning mass transfer. This book brings valuable references for researchers and engineers working in the variety of mass transfer sciences and related fields. Since the constitutive topics cover the advances in broad research areas, the topics will be mutually stimulus and informative to the researchers and engineers in different areas.

\title{
How to reference
}

In order to correctly reference this scholarly work, feel free to copy and paste the following:

Orhan Sahin and Alexandre V. Ribalko (2011). Electrospark Deposition: Mass Transfer, Mass Transfer Advanced Aspects, Dr. Hironori Nakajima (Ed.), ISBN: 978-953-307-636-2, InTech, Available from: http://www.intechopen.com/books/mass-transfer-advanced-aspects/electrospark-deposition-mass-transfer

\section{INTECH}

open science | open minds

\section{InTech Europe}

University Campus STeP Ri Slavka Krautzeka 83/A 51000 Rijeka, Croatia Phone: +385 (51) 770447 Fax: +385 (51) 686166 www.intechopen.com

\section{InTech China}

Unit 405, Office Block, Hotel Equatorial Shanghai No.65, Yan An Road (West), Shanghai, 200040, China 中国上海市延安西路65号上海国际贵都大饭店办公楼405单元 Phone: +86-21-62489820

Fax: $+86-21-62489821$ 
(C) 2011 The Author(s). Licensee IntechOpen. This is an open access article distributed under the terms of the Creative Commons Attribution 3.0 License, which permits unrestricted use, distribution, and reproduction in any medium, provided the original work is properly cited. 